\title{
Social Structure and Cultures of Corruption
}

\author{
Christopher Kingston ${ }^{1}$ \\ Department of Economics, Amherst College, Amherst MA 01002, USA.
}

\begin{abstract}
Corruption often creates a "briber's dilemma": each of the "clients" competing for a rent allocated by a government official has an incentive to pay bribes to try to obtain preferential treatment, but they would all be better off if they could mutually commit not to pay bribes. This paper uses a model of linked games to show how informal relationships among the clients may enable them to enforce agreements (or norms) against paying bribes, and how historical events can lead to the development of a "culture" of corruption which can subsequently prove hard to dislodge.
\end{abstract}

JEL classification: K42, D73, Z13

Keywords: Corruption, Social Structure, Bribery, Linked Games.

1 Email address: cgkingston@amherst.edu. Telephone (413) 542-5139. Fax (413) 542-2090. I am grateful to Masahiko Aoki, James Fearon, Avner Greif, Anjini Kochar, Anne Krueger and seminar participants at Stanford and the 2005 Public Choice Society meetings for comments on earlier drafts. For financial support, I thank the Lynde and Harry Bradley Foundation, and the John M. Olin Program in Law and Economics, Stanford Law School.

Preprint submitted to Elsevier Preprint 7 September 2005 


\section{Social Structure and Cultures of Corruption}

\section{Introduction}

Although many developing countries have inherited or adopted formal legal, political and administrative systems similar to those in the developed world, the behavior induced by these rules has often differed from that prescribed. In many cases, the observed behavior is "corruption". But why do countries with similar formal rules experience different levels of corruption? Why do transplants of formal rules from one country to another often fail to reproduce the desired patterns of behavior? Why is entrenched corruption often difficult to eliminate?

In general terms, one possible explanation is that different sets of "informal rules" can interact with a given set of formal rules to produce a variety of behaviors and outcomes. According to North (1990), the interaction between formal and informal rules also provides the key to understanding why institutional change is often characterized by inertia and path-dependence, so that changes in formal rules may lead to new and unexpected outcomes. However, neither of these phenomena - the static interaction between formal and informal rules, and the dynamic effect of informal rules on institutional evolution - is well understood. What are the relevant aspects of informal rules, where do they come from, and how do they change? How do they affect the operation of formal rules, and can anything be done to channel them for beneficial purposes or to immunize formal rules against their damaging effects?

This paper uses a simple linked-games model to explore one way in which the patterns of informal interaction in a society can affect the level of corruption, 
and then uses the model to show how a "culture" of corruption might develop, where culture is viewed not as an exogenous influence on behavior or preferences, but as an endogenous and path-dependent reflection of equilibrium strategies.

The basic idea is as follows: suppose that a government official has the power to allocate a fixed rent among several "clients" (which might be individuals, firms, villages, or ethnic groups, for example, depending on the context). If the official is corrupt, then the clients face a collective action problem: each has an incentive to pay bribes to try to capture the rent, but they would all be better off, on average, if they could mutually commit not to pay bribes. della Porta and Vannucci (1999:204) refer to this as the "briber's dilemma". This paper argues that the clients' ability to overcome the briber's dilemma may depend on the amount of informal (self-enforcing) social or economic interaction between them in other games.

For example, suppose that the individuals caught in a briber's dilemma also informally "trade" with each other in a technologically unrelated game. Then, if the trade relationship is sufficiently valuable, they can threaten to punish bribery by suspending trade. More generally, even if those caught in a briber's dilemma do not interact directly, third-party (community) enforcement may enable them to sanction (and therefore "trust") each other. Therefore, the clients' ability to overcome corruption may depend on the kind of social structure in which they are embedded.

Finally, we will consider what happens as the (exogenous) parameters which determine the set of technologically feasible equilibria change over time. Depending on the timing of parameter shifts, path-dependence can arise, so that the level of corruption is ultimately determined not only by parameter values but also by the historical parameter path. In particular, a "culture" of corruption may develop, and subsequently prove difficult to dislodge. 


\subsection{Related literature}

Given the difficulty involved in defining, let alone measuring, social structure, culture, and corruption, it is perhaps surprising that the dominant approach to these questions in the existing literature involves cross-country regressions (see Lambsdorff 2005 for a survey of the empirical literature on corruption). One strand of this literature has found that a variety of "cultural" variables, such as social capital, trust, and ethnolinguistic fractionalization, are correlated with corruption indices. ${ }^{2}$ Other studies have found that "the distant past appears as important as - or more important than - current policy" in determining the level of corruption (Treisman 2000:401), and that formal legal systems which were transplanted are considerably less effective than those which arose indigenously out of a "demand for law" (Berkowitz et al., 2000). Yet, as RoseAckerman (1999: 3-4) observes,

Cross-country empirical work... is of little use in designing anti-corruption strategies... In fact, it is not even clear what it means for a country to rank highly on a corruption index... The surveys give no information that would help one understand their underlying meaning.

The interpretation of cultural variables like "social capital" or "trust" is also problematic. Recent studies have suggested that there may be several distinct kinds of "social capital". ${ }^{3}$ Beugelsdijk and Smulders (2003) find that the

$\overline{2}$ See, eg., Temple and Johnson (1998); ("trust"); Knack and Keefer (1997) ("social capital"); Licht, Goldschmidt and Schwartz (2003) ("cultural values"); Easterly and Levine (1997) (ethnolinguistic fractionalization).

3 For example, Putnam (2000)'s distinguishes between "bridging" social capital which links members of different groups and "bonding" social capital within groups; Knack (2003) distinguishes between Putnam groups and Olson groups; Kumar and Matsusaka (2004) discuss the difference between "village" and "market" social capital. 
different kinds of social capital to some extent crowd each other out (societies with lots of "bonding" social capital have less "bridging" social capital, and vice versa). ${ }^{4}$

The idea that informal rules can affect the quality of government is not new. Putnam (1993: 167) argued that "social capital" can improve the quality of government by facilitating "spontaneous cooperation". 5 Uslaner (2005) argues that a "culture" of corruption may be a result of a more general "culture of mistrust" in a society because "(p)eople who have faith in others are more likely to endorse strong standards of moral and legal behavior" (p.76).

Yet there have been few theoretical studies of how informal rules might affect the level of corruption. Understanding the links is particularly important for generating policy implications, because given that many aspects of informal rules are essentially impervious to policy (notwithstanding frequent entreaties to "build social capital" in the literature), it is important to design formal rules in a way which takes account of a society's informal rules. For this, simply knowing that "social capital reduces corruption" is not enough; we have to know how.

Bjornskov (2003) models a causal relationship between "social capital" and corruption. In his model, "social capital" is viewed as the proportion of honest "types" in the population (social capital reduces corruption). This paper's approach differs in that here, trustworthy behavior arises as an outcome of strategic interaction in repeated games, rather than an internalized feature of individual preferences.

$\overline{4}$ Kingston (2004) carries out an empirical test which attempts to avoid some of these problems.

5 Since he defines social capital as "features of social organization ... that can improve the efficiency of society by facilitating coordinated actions" (ibid), this is somewhat tautological. 
Djankov et al. (2003) present a framework in which the set of institutions available to a country depends on their stock of "civic capital", which is a broad category including technology, factor endowments, human and social capital, and culture. They argue that societies with more civic capital "are capable of achieving more cooperation among their members" (p.600) and therefore are capable of choosing more efficient institutions than societies with less civic capital. The present paper provides an explicit mechanism linking one aspect of civic capital with one aspect of institutional quality; and provides a rationale for why a society may not always "choose" institutions on the efficient institutional possibility frontier.

Kingston (forthcoming) argues that informal ties between officials and members of the public may enable them to enforce bribe transactions and engage in "parochial corruption" (favoritism towards kinsmen). This paper, in contrast, argues that informal ties can be used to enforce agreements not to pay bribes. So which is it? The key to resolving the apparent contradiction lies in distinguishing between two different kinds of social structure. The strong informal ties within disjoint groups which characterize a collectivist social structure may facilitate parochial corruption, but cannot be used to enforce broader social norms against bribery when individuals from different groups are involved. Conversely, the broader "civic" social ties prevalent in an integrated social structure can more readily be used to enforce broader anti-bribery norms, but are less likely to provide particular individuals with an "inside track".

The claim that "history matters" is also not new. For example, Putnam makes a striking claim of path-dependence concerning regional differences in "norms and networks of civic engagement" in Italy: "social patterns plainly traceable from early medieval Italy to today turn out to be decisive in explaining why, on the verge of the twenty-first century, some communities are better able than others to manage collective life and sustain effective institutions" (1993:121). But how history matters, and when, is less well understood. Sev- 
eral sources of path-dependence have been identified in the literature: ${ }^{6}$ past institutions affect future institutions because they provide the environment in which players learn, invest in skills, form "mental models" of the world, build networks, organizations and interest groups, and learn about the strategies of other players.

This paper focuses on the role of earlier institutions in equilibrium selection in subsequent games. Myerson (1991:113) defines cultural norms as "the rules that a society uses to determine focal equilibria in game situations" (see also Greif 1994). This paper argues that past equilibria constitute cultural norms in this sense, which can affect equilibrium selection in future games and thereby lead to path-dependence.

The paper proceeds as follows. Section 2 presents a simple model which formalizes the argument that informal contact in other games can enable clients to more easily overcome a briber's dilemma. Section 3 applies the model to explore the effect of social structure on corruption. Section 4 uses the model to show how a "culture" of corruption might arise following inter-society transplants of formal rules. Section 5 concludes.

\section{Model}

This model uses an infinitely-repeated game to show how patterns of interaction among the clients of a bureaucracy can affect officials' incentives to engage in corruption. The model is based on the idea of strategic linkage: when the same individuals encounter each other in several different repeated games, they can make their actions in one game contingent on their opponents' actions in another game, thereby "pooling" the incentive constraints across games (Bernheim and Whinston 1990).

$\overline{6}$ eg., Acemoglu et al. (2002); della Porta and Vannucci (2005); North (2005). 


\subsection{Briber's Dilemma}

Consider the following one-shot "briber's dilemma" game. A government official allocates an indivisible rent worth $R$ to one of $N$ "clients", indexed by $i \in\{1,2, \ldots, N\}$. All players are risk-neutral and discount future payoffs at a rate $\delta$. An allocation is a vector $\left(\alpha_{1}, \alpha_{2}, \ldots, \alpha_{N}\right) \in\{0,1\}^{N}$ such that $\alpha_{i} \in\{0,1\} \forall i$ and $\sum_{i=1}^{N} \alpha_{i}=1$, where $\alpha_{i}=1$ if the rent is allocated to client $i$, and zero otherwise. Let $A$ denote the set of possible allocations and let $P(A)$ be the set of probability distributions over $A$. Assume that government policies specify formal rules governing the allocation of the rent, and that the impartial application of these rules gives rise to a probability distribution over allocations $\vec{\gamma}=\left(\gamma_{1}, \gamma_{2}, \ldots, \gamma_{N}\right) \in P(A) . \vec{\gamma}$ is common knowledge. Let $\gamma_{\min }=\min \left(\gamma_{i}\right)_{i=1}^{N}$ denote the smallest expected formal entitlement among the $N$ clients.

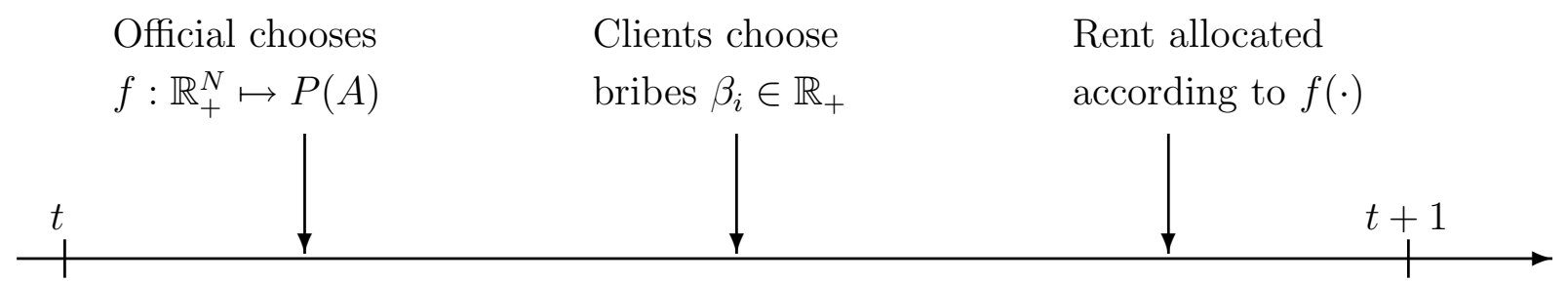

Fig. 1. Time line, briber's dilemma

The order of play in each period is as follows. First, the official "builds the game", by announcing a function $f: \mathbb{R}_{+}^{N} \mapsto P(A)$ which maps the non-negative bribes $\vec{\beta}=\left(\beta_{1}, \ldots, \beta_{N}\right)$ paid by the clients into a probability distribution over allocations $f(\vec{\beta}) \in P(A)$. We impose the restriction that $f(0,0, \ldots, 0)=\gamma_{i}$ (that is, if the clients do not pay bribes, the official allocates the rent honestly; this is a simplifying assumption only). Second, each 
of the clients chooses the amount of their bribe, if any. Third, the rent is allocated according to $f(\cdot)$ and the stage game ends.

The "honest" choice for the official is $f(\vec{\beta})=\vec{\gamma}$, which can be interpreted as an announcement that the official "will not accept" bribes. If the official chooses any $f(\vec{\beta}) \neq \vec{\gamma}$ we will say that he has acted corruptly, in which case, with probability $\phi$ he suffers a punishment (fine) $F$, where $\phi$ and $F$ are exogenous, and can be taken to reflect monitoring behavior by the official's superiors. Let $f_{i}(\vec{\beta})$ denote the $i^{t h}$ component of $f(\vec{\beta})$; that is, $f(\vec{\beta})=\left(f_{1}(\vec{\beta}), f_{2}(\vec{\beta}), \ldots, f_{N}(\vec{\beta})\right)$. Then the expected payoffs to the clients and the official are, respectively,

$$
\begin{array}{rlr}
\Pi_{i}(\vec{\beta}) & =f_{i}(\vec{\beta}) R-\beta_{i} & i \in\{1, \ldots, N\} \\
\Pi_{\text {official }}(\vec{\beta}) & = \begin{cases}\sum_{i=1}^{N} \beta_{i} & \text { if } f(\vec{\beta})=\vec{\gamma} \\
\sum_{i=1}^{N} \beta_{i}-\phi F & \text { if } f(\vec{\beta}) \neq \vec{\gamma}\end{cases}
\end{array}
$$

Lemma 2.1. In a one-shot briber's dilemma, if $\phi F>R$, then there is a unique subgame-perfect equilibrium in which the official chooses $f(\cdot)=\vec{\gamma}$. If $\phi F<R$, there are many subgame-perfect equilibria, in all of which the official chooses $f(\cdot) \neq \vec{\gamma}$ and the clients receive expected payoffs of zero. If $\phi F=R$, both types of equilibria exist.

Proof. If the official chooses $f(\cdot)=\vec{\gamma}$, then the dominant strategy equilibrium in the resulting subgame is $\beta_{i}=0 \quad \forall i$, so the payoff to the official in equilibrium is 0 . If the official acts corruptly, on the other hand, there are numerous ways for him to specify $f(\cdot)$ in order to capture the whole of the rent in a oneshot game. For example, if he chooses $f$ such that $f_{i}(\vec{\beta})=\frac{\beta_{i}^{\left(\frac{N}{N-1}\right)}}{\sum_{j=1}^{N} \beta_{j}^{\left(\frac{N}{N-1}\right)}}$, then all clients pay bribes of $R / N$ in the unique Nash equilibrium of the resulting subgame, and the official's expected payoff is $R-\phi F$. Or, if he simply sells the rent to the highest bidder, then, in any Nash equilibrium of the resulting subgame, at least two clients will bid $R$. Thus, if $\phi F<R$, any choice of $f(\cdot)$ 
which does not enable the official to obtain bribes totalling $R$ is not subgame perfect, and therefore, the expected payoff to the clients in equilibrium is 0 . If $\phi F>R$, however, then the official strictly prefers to act honestly. If $\phi F=R$, the official is indifferent.

The interesting case is the one in which the monitoring by the official's superiors is insufficient to deter corruption, ie., $\phi F<R$. In the remainder of the paper, we assume this holds. In this case, a one-shot briber's dilemma presents the clients with a collective action problem. If they could mutually commit not to pay bribes, their vector of expected payoffs would be $\vec{\gamma} R$, whereas their subgame-perfect equilibrium payoff is 0 .

Of course, if the game is repeated sufficiently often, the clients may be able to achieve the cooperative outcome. Suppose the briber's dilemma is expected to be played in each future period with probability $p$ (thus, if $p=1$, we have a standard infinitely-repeated game; if $p=0$, we have a one-shot game).

Lemma 2.2. Assume $\phi F<R$. In a briber's dilemma which occurs with probability $p$ in each period, a subgame perfect equilibrium in which the official chooses $f(\vec{\beta})=\vec{\gamma}$ exists if and only if

$$
1-\gamma_{\min } \leq \frac{\delta p \gamma_{\min }}{1-\delta}
$$

Proof. Consider a grim trigger strategy: the clients attempt to sustain a path of play in which they all pay no bribes, threatening Nash reversion following any defection. Since all players receive a payoff of zero in a one-shot subgameperfect equilibrium, this is an optimal penal code (Abreu 1988). Suppose the official simply offers the rent to the highest bidder. This provides the maximum incentive for a client to defect from the non-bribing agreement, since by paying an infinitesimal bribe, she can obtain the whole of the rent (we are assuming that the official cannot commit to particular choices of $f(\cdot)$ in future periods). The incentive-compatibility constraint binds most tightly on the client with 
formal entitlement $\gamma_{\min }$, who has most to gain $\left[\left(1-\gamma_{\min }\right) R\right]$ and least to lose $\left[\gamma_{\min } R\right.$ with probability $p$ in each future period] from defection. Therefore, non-bribery can be sustained by a grim trigger strategy if and only if (1) holds. If the clients can sustain such a strategy, then the official prefers to act honestly in order to avoid the chance of punishment $\phi F$.

Note that if $p$ is sufficiently low (the game is played infrequently), or $\gamma_{\min }$ is sufficiently low (one of the clients is very unlikely to be formally entitled to receive the rent), a non-corrupt equilibrium cannot be sustained even through repetition of the game.

\subsection{Trade}

Suppose now that in addition to the briber's dilemma, the clients also engage in a self-enforcing social or economic interaction, which we will call "trade". "Trade" might represent a variety of social or economic interactions; the key feature of trade is that enforcement is informal, in the sense that opportunism is constrained by the "trust" generated through repeated interaction, rather than by a third party.

The trade game is as follows. At the start of each period, each client $i$ chooses a vector of actions $\overrightarrow{a_{i}}=\left(a_{i 1}, a_{i 2}, \ldots, a_{i(i-1)}, a_{i(i+1)}, \ldots, a_{i N}\right)$ where each $a_{i j}$ can take one of two possible values: zero (defect) or 1 (cooperate). The payoff to client $j$ is

$$
\Pi_{j}\left(\overrightarrow{a_{1}}, \overrightarrow{a_{2}}, \ldots, \overrightarrow{a_{N}}\right)=(u+z) \sum_{i \neq j} a_{i j}-u \sum_{i \neq j} a_{j i}
$$

That is, by choosing $a_{i j}=1$ client $i$ provides client $j$ with $(u+z)$ units of utility, at a cost to himself of $u$ units of utility. The parameter $z$ reflects the net benefit from trade, if any (which might depend on technology, infrastructure, literacy, social structure, income, etc., depending on the context). The trade

game can also be viewed as a network of $\frac{N(N-1)}{2}$ bilateral prisoner's dilemmas 
played between the pairs of clients, with payoffs:

\begin{tabular}{l|r|c|}
\multicolumn{1}{c}{} & \multicolumn{1}{c}{ Cooperate } & Defect \\
\cline { 2 - 3 } Cooperate & $u+z, u+z$ & $0,2 u+z$ \\
\cline { 2 - 3 } Defect & $2 u+z, 0$ & $u, u$ \\
\hline
\end{tabular}

In some settings, it may be more appropriate to imagine the clients taking a single action which affects all other group members. This would simply add a technological restriction that $a_{i j}=a_{i k} \quad \forall i, j, k$

Lemma 2.3. An equilibrium in which $a_{i j}=1 \quad \forall i, j$ can be sustained as a subgame-perfect equilibrium if and only if

$$
\frac{\delta z}{1-\delta}>u
$$

Proof. Suppose all pairs of clients play grim trigger strategies in each bilateral interaction. Then by failing to cooperate, a client can gain $u$, at a cost of $z$ in each future period. (Community enforcement adds nothing here because the bilateral interactions are assumed to be identical and simultaneous).

Definition $S(u, z, \delta)$ is the "slack" (or "social capital") from the trade game:

$$
S(u, z, \delta)=\left(\frac{\delta}{1-\delta} z-u\right) N
$$

\subsection{Strategic Linkage}

In principle, the briber's dilemma is technologically distinct from trade, and the two games might be treated as strategically unrelated. However, players who found themselves playing a briber's dilemma would have a natural incentive to strategically link the games, if they could avoid having to pay bribes by 
"staking their reputations" in the trade game on their behavior in the briber's dilemma.

Therefore, suppose that the games are played simultaneously, according to the timeline depicted in Figure 2. The trade game is repeated each period, and the briber's dilemma is played each period with probability $p$.

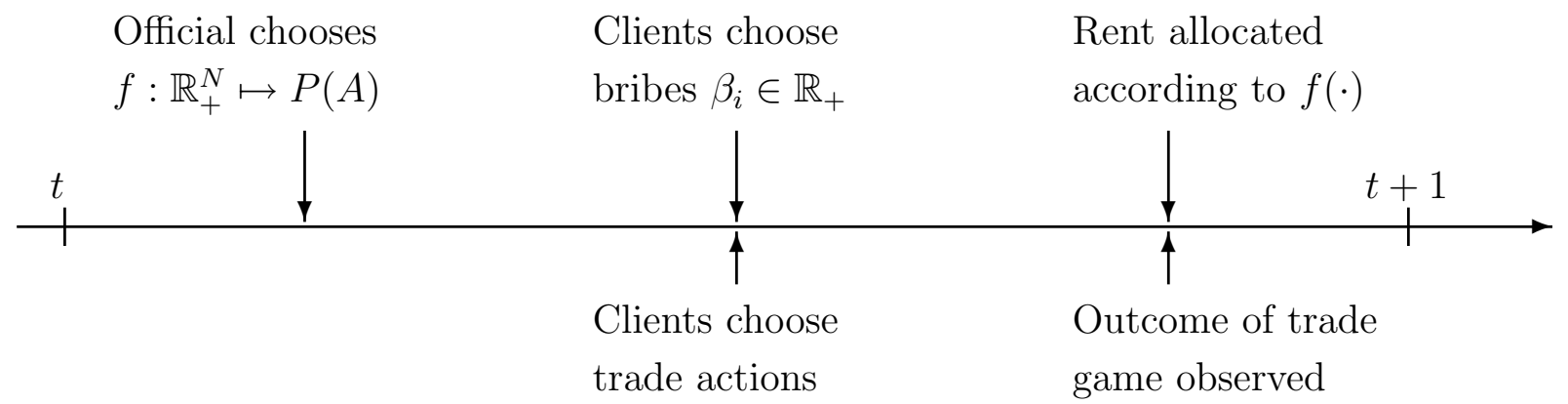

Fig. 2. Time line, linked games

Proposition 1. Assume $\phi F<R$, and the clients in a briber's dilemma which occurs with probability $p$ in each period also play the trade game each period. A subgame perfect equilibrium in which the official chooses $f(\vec{\beta})=\vec{\gamma}$ exists if and only if

$$
\frac{S(u, z, \delta)}{R} \geq 1-\gamma_{\min }-\frac{\delta p \gamma_{\min }}{1-\delta}
$$

Proof. Suppose the clients adopt a strategy of punishing a trader, $k$, who pays a bribe not only by Nash reversion in the briber's dilemma, but also by setting $a_{i k}=0$ for all $i$ in all future trades. This is subgame perfect. With this enforcement regime, a player planning to pay a bribe also has an incentive to simultaneously defect in the trade game (since he stands to lose his "reputation" anyway). If an official acts corruptly (for example, by offering the rent to the highest bidder), and all other players are expected to adhere to this strategy, then player $i$ has an incentive to defect unless

$$
R+N(u+z) \leq \gamma_{i} R+\frac{\delta}{1-\delta} p \gamma_{i} R+\frac{1}{1-\delta} N z
$$


This incentive constraint binds most tightly on the player with the smallest expected formal entitlement to the rent, $\gamma_{\text {min }}$, whose incentive constraint simplifies to (3). Therefore, the clients can enforce an agreement (or an implicit norm) not to pay bribes if and only if (3) holds.

Comparing (3) with (1), it is clear that strategic linkage relaxes the incentive constraints, helping to make a non-bribing equilibrium enforceable, for all values of $p$ and $\gamma_{\min }$, and may even enable non-bribery to be sustained if $p=0$ or $\gamma_{\min }=0$.

Note that if the clients adopt a norm against paying bribes, then in equilibrium, the official will not ask for bribes, since doing so involves a risk of punishment. Thus, the level of corruption is determined by the interaction between formal and informal rules: the official's behavior depends in part on formal rules (the likelihood of punishment, the size of the rent and the rules governing its allocation), and in part on the strength of the informal relationships among the clients.

To illustrate Proposition 1, consider a situation in which several firms in an industry compete for contracts or licenses, or can bribe officials to overlook regulations or to avoid taxes or excise. A firm which refuses to pay bribes risks being priced out of the market by less scrupulous competitors. As a result, these firms face a collective action problem. If some firms engage in bribery, the others have little choice but to follow suit.

However, suppose the firms form an association to undertake mutually beneficial activities such as sharing information, lobbying, setting industry standards, or price collusion. Proposition 1 suggests that the threat of expulsion from the association might enable the firms to escape their collective action problem, coordinate opposition to officials seeking bribes, and enforce boy- 
cotts of firms found to be paying them. ${ }^{7}$ For this to work, several conditions must be met: the benefits to membership must be valuable and excludable; defection must be detectable (at least with some probability) and all (or at least a large proportion) of the firms in the industry must be included.

For example, Kochanek (1993, esp. chs. 12 \& 13) found that in Bangladesh, business associations were too weak to prevent government policies being undermined by individual firms seeking exemptions: "The exceptions to existing policy are so specific that any knowledgeable observer can easily identify the individual or firm receiving the benefit." (Kochanek 1993:252). Similarly, della Porta and Vannucci found that in Italy, individual firms faced reprisals from officials if they denounced corruption, but "a collective denunciation, the only way out, was made impossible by the lack of reciprocal confidence among entrepreneurs." (1999:206)

The empirical studies collected in Maxfield and Schneider (1997) contain several similar examples, but also some examples of situations in which firms successfully used business associations to overcome corruption. For example, among an association of clothing manufacturers in Turkey,

Members who contemplate circumventing the association to seek particularistic benefits have to weigh the likelihood and costs of losing membership in the association against the likely benefits from private relations with government officials. (Maxfield and Schneider 1997:24)

Maxfield and Schneider argue that an ability to provide concrete benefits to members and to exclude individual firms from those benefits was important in order for business associations to be able to enforce agreements, and thereby overcome individual firms' rent-seeking incentives (ibid:21). Associations also

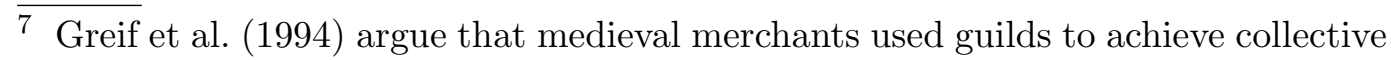
action in a related context. 
needed to be "encompassing" in the sense of including a large proportion of the relevant firms.

\section{Social Structure and Corruption}

Since Putnam (1993) argued that "social capital" can improve the quality of government, empirical studies have confirmed that various aspects of a society's "informal rules" are correlated with measures of corruption and bureaucratic inefficiency (see footnote 2). Yet, the ways in which formal and informal rules interact are still imperfectly understood (North 1990).

One possible application of the model is to a situation in which the "clients" represent internally cohesive social or ethnic groups, and "trade" represents informal interaction between members of different groups. With this interpretation, our model can be seen as identifying a mechanism by which a particular form of social capital (trust generated through repeated interaction in other games) can improve the quality of government by enabling these groups to enforce anti-bribery agreements (possibly socially experienced as implicit "social norms" against bribery). ${ }^{8}$

In many cases, of course, it is not "groups" themselves, but individuals within groups, who will play briber's dilemmas. If the value of the rent is substantial, it may seem unlikely that the amount of direct informal interaction between such individuals will be sufficient to deter corruption. However, suppose the players adopt a "collective responsibility" norm, according to which, when a member of a group cheats a member of another group, all the members of the defectors group are "tarred with the same brush" and punished. Such a norm substantially increases the amount of informal pressure which can be brought

8 For models investigating the effects of social structure on trust and economic performance, see Greif (1994), Kali (2002) and Dixit (2003) 
to bear on an individual considering defection, and thereby increases the degree to which members of different groups can trust each other. ${ }^{9}$ Two things are required for such a norm to work. First, there must be a sufficient amount of repeated interaction (trade and/or briber's dilemmas) between members of the two groups; and second, the groups must be internally cohesive so that they can discipline their members. In this instance, "bonding" and "bridging" social capital may be complementary.

Economic anthropologist T. Scarlett Epstein's $(1962,1998)$ study of two South Indian villages illustrates how social structure can affect a community's relationships with government officials. The two villages studied initially had similar economies and were similar in size and caste composition, being dominated by a peasant caste but also containing some service castes (blacksmiths, potters, etc.) and dalits (former untouchables) who traditionally provided services and agricultural labor for the peasants. However, an exogenous ${ }^{10}$ technological change, namely the introduction of canal irrigation, caused the paths of development in the two villages to diverge.

In the first village, canal irrigation was introduced in 1939. This prompted villagers to begin cultivating irrigated crops such as sugar cane, which are more profitable but also more labor intensive than dry crops. In this way, the use of irrigation led to increased economic interdependence among the villagers, enabling them to enforce mutual cooperation by threat of economic sanctions. ${ }^{11}$ This mutual interdependence enabled the different groups within

$\overline{9}$ For models and applications of collective-responsibility norms, see Fearon and Laitin (1996) and Greif (1999).

${ }^{10}$ Epstein (1962:5-7,311). A government-constructed dam irrigated all villages within a large area.

11 This was illustrated by a lockout which persisted until "both Peasant employers and Untouchable laborers found the situation economically untenable" (Epstein 1962:187). 
the village to interact (relatively) harmoniously, and facilitated the building of a new secondary school, health centre and veterinary dispensary (Epstein et al. 1998:61,150,227). Villagers also cooperated to keep external authorities out of internal village affairs, and presented a "united front" when dealing with government officials (Epstein 1962:143):

Villagers refused to let the Government set them to competing with each other; their feeling of unity as against the Government outweighed the economic interests of individual villagers (1962:145)

In contrast, the irrigation canals bypassed the second village, because it lay above the canal water level, on the fringe of the "irrigated belt" of villages. So, when irrigation was introduced, many village residents purchased irrigated fields in neighboring villages, or obtained employment outside the village, providing services for members of irrigated villages (such as transporting sugar cane to the refinery). Social and economic interaction within the village decreased, and this reduced the villager's capacity for collective action. Village amenities such as schools and temples were allowed to deteriorate, and villagers used personal contacts, caste loyalty, and bribery to try to get government officials and police to intervene on their behalf in internal disputes (mostly disputes over land). ${ }^{12}$

The contrasting experiences of these two villages illustrate how informal social or economic interaction, which can be viewed as a form of social capital, can provide the strategic foundation for a "civic society" in which people or firms can trust one another not to pay bribes. Lacking an ability to informally sanction each other in other games, members of a less integrated community (such as the non-irrigated village) are more likely to seek preferential treatment from government officials at each other's expense.

$\overline{12}$ Epstein et al. (1998: 123, 157-8, 202, 231, 283-4, 288-90). 
The link between social structure and corruption suggests a possible answer to the puzzle of why the level of corruption is lower in the West than in developing countries, despite the fact that government expenditure in the West is generally considerably higher (as a percentage of GDP), so that in crosscountry comparisons, larger governments are generally less corrupt (La Porta et al 1999:239). Part of the explanation may lie in the contrast between the integrated social structure of the developed world and the comparatively more collectivist social structures associated with lower levels of development.

\section{Cultures of Corruption}

Proposition 1 gives the conditions under which clients can use their informal "trade" relationships to enforce non-bribing agreements. If $S(\cdot)$ is low relative to $R$, the limited benefits from trade are insufficient to sustain anti-bribery norms through strategic linkage. At higher levels of $S(\cdot)$, the value of trade is sufficient to potentially support a cooperative (non-bribing) equilibrium. However, even in this case, there also exists a "corrupt" equilibrium in which no strategic linkage occurs. Figure 3 illustrates this multiplicity of equilibria.

If political transactions costs are low, then it may be reasonable to assume that people will co-ordinate on the most efficient equilibrium. However, in reality, political transactions costs are often high (Acemoglu 2003), and Paretoinefficient equilibria are therefore a possibility.

Suppose that an interventionist state is introduced for the first time into a society characterized by a low level of $S(\cdot)$ (which might be interpreted as a society lacking strong business associations or "civic" associations). If the

value of allocated rents, $R$, is large (point $\mathrm{B}$ ), corruption is inevitable; but if $R$ is sufficiently small (point $\mathrm{A}$ ), multiple equilibria are possible: by linking strategies across games, the members of this society can sustain non-bribery 


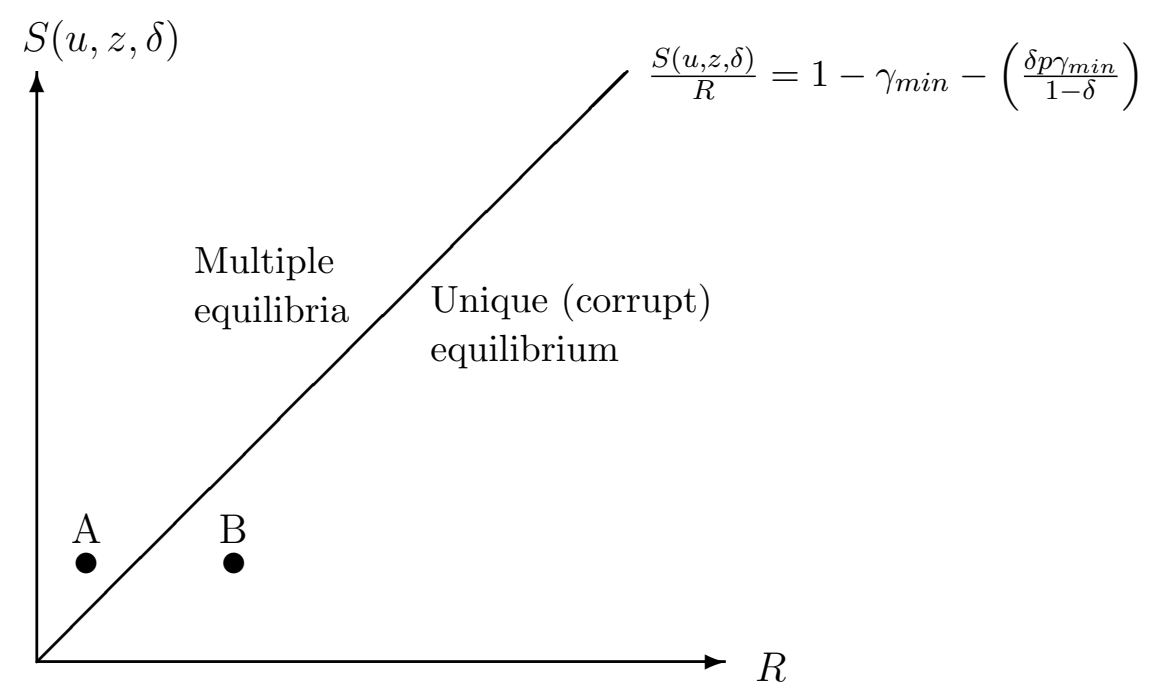

Fig. 3. The set of feasible equilibria depends on $S(\cdot)$ and $R$

in the briber's dilemma; but there also exist equilibria without such linkage, in which case bribery will occur in the rent-seeking game. Game theory, and economics in general, has little to say about what makes particular equilibria focal. Assumption 1 resolves this multiplicity.

Assumption 1. In novel situations, pareto-superior equilibria are focal.

Under Assumption 1, the inhabitants of a society into which a small- $R$ state is introduced will coordinate on an equilibrium in which strategic linkage between the trade game and briber's dilemma sustains non-bribery in the latter. If a large- $R$ state is introduced, strategic linkage would not be sufficient to deter bribery and would jeopardize trade; therefore, under Assumption 1, an equilibrium without strategic linkage will be chosen.

Next suppose that over time, exogenous parameter changes (economic development, social change, technology, etc.) increase the level of $S(\cdot)$, but that this movement occurs gradually (so that at any moment, the players treat the parameters as fixed from one period to the next). At some point, a non-corrupt equilibrium sustained by strategic linkage will become feasible (if it was not 
already). But will it be observed? The state is no longer a novel institution, and the players' shared historical experiences can become "cultural norms" 13 influencing equilibrium selection in the new situation. Assumption 2 captures this idea.

Assumption 2. In familiar (non-novel) situations, equilibria qualitatively similar to previously observed equilibria are focal.

Assumption 2 ensures that once an equilibrium is being played it will continue to be played until something happens to create a coordinated shift of expectations or to make the original equilibrium infeasible. So, a society in which a corrupt equilibrium has been established may continue to experience corruption even after $S(\cdot)$ increases to the point where (3) holds, despite the fact that this equilibrium is now pareto-dominated by a newly feasible cooperative equilibrium characterized by strategic linkage.

More generally, observed equilibria may depend on the historical evolution of the vector of parameters $(R, S(u, z, \delta))$. Thus, for example, in Figure 4, different equilibria would be observed at point $\mathrm{C}$ depending on whether a society-economy has moved from A to C along path I or path II.

To make the point more concrete: if previous experiences have left people cynical about corruption, this may give rise to a "culture" of corruption which leads to the selection of a "low-trust" equilibrium, in which corruption is both expected and observed, even after a high-trust equilibrium has become technologically feasible.

All of this assumes that the shifts in $S(\cdot)$ and $R$ are exogenous. But in reality, the evolution of these parameters may also be affected by the equilibrium of

\footnotetext{
$\overline{13}$ Myerson (1991:113) defines cultural norms as "the rules that a society uses to determine focal equilibria in game situations"; see also Putnam (1993) and Greif (1994).
} 


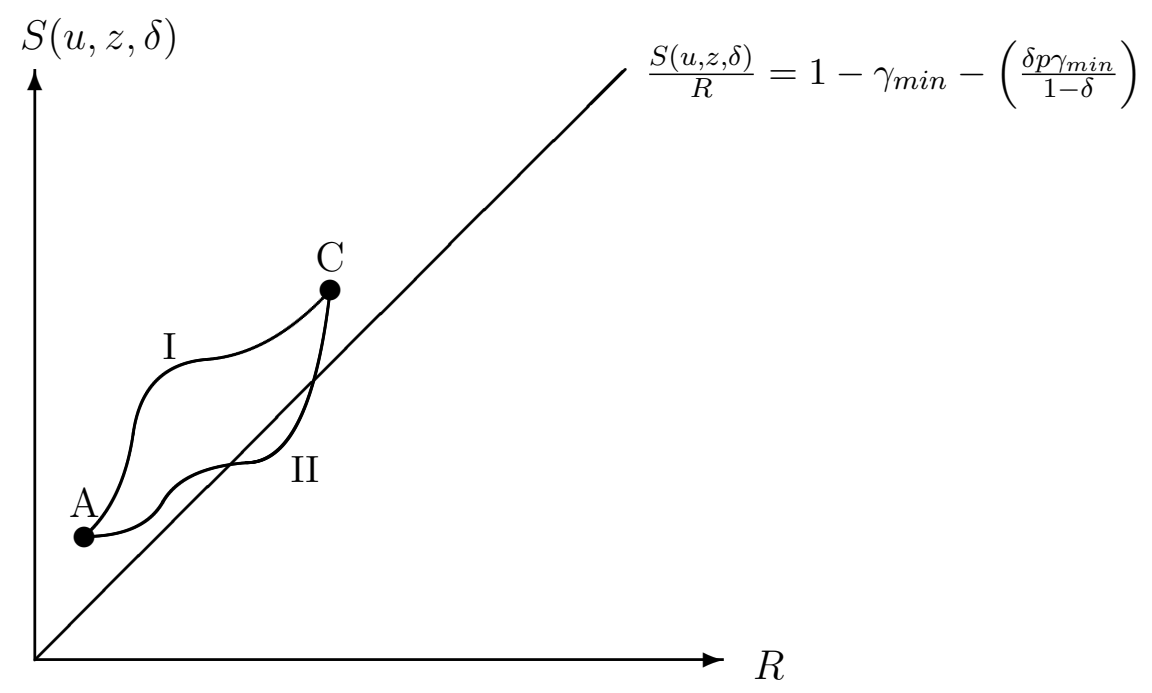

Fig. 4. The equilibrium observed at $\mathrm{C}$ depends on the historical parameter path the game. For example, because corruption causes insecure property rights in transactions which require formal enforcement, individuals in a society governed by a corrupt formal system will tend to deal mainly with those with whom they have existing informal relationships. This may reinforce a collectivist social structure, which reinforces the corrupt equilibrium, creating the potential for a development trap.

\subsection{Britain and India}

Many developing countries have "formal rules" which did not arise indigenously, but instead were largely transplanted from the West (in many cases, from their former colonial masters). A central puzzle for institutional economics is understanding why such transplants often fail. But what exactly was transplanted? There is no single answer: transplants included everything from political systems (democracy, communism, the nation state), to laws and legal systems (civil or common law), to administrative structures, and more intangible influences such as language and sports. However, one key reason for 
the failure of institutional transplants was that they led to inefficiently high levels of regulation and state ownership in the recipient countries (Djankov et al 2003: 610-11).

With this (admittedly rather sweeping) interpretation of the effect of institutional transplants, our model can shed light on the comparative historical experiences of Britain and India. Evidently, this can only be done in very general terms, so the following is intended to be merely suggestive.

In Britain, a (comparatively) low-corruption equilibrium was established by a series of reforms during nineteenth-century (Wraith and Simpkins 1963:93). By the time that the scope of state intervention approached its modern levels in the mid-twentieth century, a great deal of social and economic change associated with modernization, including economic integration, the formation of a national identity, and the development of civic associations and middle classes had already occurred. As the role of the state expanded in a (comparatively) technologically advanced and "integrated" society, a low-corruption equilibrium was preserved.

In nineteenth-century India, the formal legal and administrative system was largely transplanted from Britain over an extended period of time, and initially, these institutional transplants were generally successful (Lipstein 1957). The British colonial administration generally concentrated on revenue collection, defense, and the maintenance of British rule, without taking an active role in development, and the upper levels of the administration (staffed mainly by British expatriates) were generally considered incorruptible.

However, following Independence, extensive controls were introduced on private sector economic activity, including production, trade, foreign exchange, access to credit, rent, and use of land. Government expenditure increased substantially, and a planning commission was established to direct investment. This increase in state intervention occurred in the context of a predominantly 
rural and unintegrated society with weak business and civic associations and strong caste, religious and ethnic identities. In terms of our model, by raising the rewards to rent-seeking relative to the rewards to innovation and productive activity, an increase in $R$ may have "broken" the (comparatively) low-corruption equilibrium established under the colonial administration, and given rise to a "permit-license-quota raj" characterized by a substantial increase in the level of corruption.

Despite many efforts at reform, and despite a substantial increase in the levels of literacy, voting, social integration and economic development, this equilibrium has subsequently proven difficult to dislodge, suggesting that when commentators bemoan the "culture" of corruption in India, they may be correct, not in the sense that there are exogenous "cultural values" tolerant of corruption, but in the sense that alternative, less corrupt equilibria may be feasible; the level of corruption is not fully determined by parameters, but may also reflect historically-derived shared expectations.

\subsection{Escaping the trap}

Why is a corrupt equilibrium often difficult to dislodge? When multiple equilibria are possible, equilibrium selection is, in effect, a multi-player coordination game. David (1986) has argued that decentralized decision-making by many individuals may trap an economy in a suboptimal equilibrium, even after its sub-optimality has become clear to the participants. Liebowitz and Margolis (1995), however, have argued that if such were the case, one player would act as an entrepreneur, coordinating a move to a superior equilibrium and extracting some of the resulting rents as profit. However, in effect, this requires an assumption of zero transaction costs, so that (by a Coase-theorem-like argument) pareto-inefficient equilibria will not arise. The empirical evidence strongly suggests that at least on a societal level, political transaction costs 
are positive, and that sub-optimal "low-trust" equilibria can both arise and persist. ${ }^{14}$

A game-theoretic take on essentially the same issue is that of renegotiationproofness. As trigger strategies in a repeated prisoner's dilemma, the "lowtrust" equilibria in our model are not renegotiation-proof; but this need not necessarily be troubling; in many situations, especially when many players are involved, renegotiation may be implausible or at least costly.

And yet, although engineering a coordinated shift in expectations is by no means trivial, successful institutional reforms do sometimes occur. One policy prescription which arises straightforwardly from multiple-equilibrium models is that "crackdowns" - attempts to shift out of a corrupt equilibrium by means of short, drastic campaigns - may work where more gradual measures would not. This paper's model supports this idea. The dynamic version of the argument also suggests a caveat, however: half-hearted reforms, or reforms undertaken "too early" (before cooperative equilibria are feasible) may not only fail to reduce the level of corruption, but may also sabotage future reform efforts. Because crackdowns are attempts to bring about coordinated shifts of expectations (a shift to a new equilibrium), a history of unsuccessful crackdowns may give rise to cynicism about the crackdowns themselves, making it all the harder to overcome corruption when conditions do finally become suitable. Therefore, reform efforts which are undertaken unwillingly and halfheartedly (for example, to satisfy international organizations or aid donors) may do more harm than good.

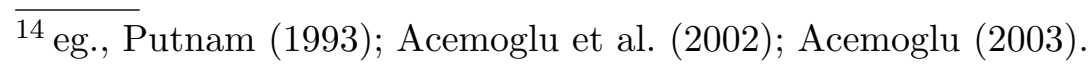




\section{Conclusion}

This paper has explored one way in which the informal relationships within a society can interact with formal rules to affect the level of corruption. The central idea is that the members of the public who deal with a potentially corrupt government official can more easily enforce agreements not to pay bribes if they have some informal social or economic contact in other games.

A puzzling feature of corruption is its persistence in many developing countries despite widespread awareness of the associated costs. This persistence has sometimes been viewed as reflecting a tolerance for corruption arising from traditional (exogenous) cultural norms. However, such norms may instead reflect underlying equilibria made possible by interactions between transplanted formal rules and indigenous informal social structures, and made focal by equilibrium selection based on historical experiences.

\section{References}

Abreu, D. (1988). On the theory of infinitely repeated games with discounting. Econometrica, 56(2):383-396.

Acemoglu, D. (2003). Why not a political coase theorem? social conflict, commitment, and politics. Journal of Comparative Economics, 31:620-652.

Acemoglu, D., Johnson, S., and Robinson, J. (2002). The colonial origins of comparative development: An empirical investigation. American Economic Review, 91(5):1369-1401.

Berkowitz, D., Pistor, K., and Richard, J.-F. (2000). Economic development, legality, and the transplant effect. Working Paper no.39, Center for International Development, Harvard.

Bernheim, B. D. and Whinston, M. D. (1990). Multimarket contact and collusive behavior. Rand Journal of Economics, 21(1):1-26.

Beugelsdijk, S. and Smulders, S. (2003). Bridging and bonding social capital: Which type is good for economic growth? Working paper, Tilburg.

Bjornskov, C. (2003). Corruption and social capital. Working paper 03-13, Aarhus School of Business. 
David, P. (1986). Understanding the economics of qwerty: the necessity of history. In Parker, W., editor, Economic History and the Modern Economist. Blackwell.

della Porta, D. and Vannucci, A. (1999). Corrupt Exchanges. Aldine de Gruyter, New York.

della Porta, D. and Vannucci, A. (2005). The governance mechanism of corrupt transactions. In Lambsdorff, J. G., Taube, M., and Schramm, M., editors, The New Institutional Economics of Corruption. Routledge, New York, NY.

Dixit, A. (2003). Trade expansion and contract enforcement. Journal of Political Economy, 111(6):1293-1317.

Djankov, S., Glaeser, E., Porta, R. L., de Silanes, F. L., and Shleifer, A. (2003). The new comparative economics. Journal of Comparative Economics, 31:595-619.

Easterly, W. and Levine, R. (1997). Africa's growth tragedy: Policies and ethnic divisions. Quarterly Journal of Economics, CXII(4):1203-1250.

Epstein, T. S. (1962). Economic Development and Social Change in South India. Manchester University Press, Manchester, UK.

Epstein, T. S., Suryanarayana, A., and Thimmegowda, T. (1998). Village Voices: Forty Years of Rural Transformation in South India. Sage, New Delhi.

Fearon, J. D. and Laitin, D. D. (1996). Explaining interethnic cooperation. American Political Science Review, 90(4):715-735.

Greif, A. (1994). Cultural beliefs and the organization of society: A historical and theoretical reflection on collectivist and individualist societies. Journal of Political Economy, 102(3):912-950.

Greif, A. (1999). On institutions that facilitate impersonal exchange: From the community responsibility system to individual legal responsibility in pre-modern Europe. Mimeo, Stanford University.

Greif, A., Milgrom, P., and Weingast, B. R. (1994). Coordination, commitment and enforcement: The case of the merchant guild. Journal of Political Economy, 102(4):745-776.

Kali, R. (2002). Social embeddedness, modernization and markets: A small world approach to economic governance. University of Arkansas.

Kingston, C. (2004). Corruption and social structure: Theory, and evidence from India. BREAD Working paper No. 75.

Kingston, C. (forthcoming). Parochial corruption. forthcoming, Journal of Economic Behavior and Organization.

Knack, S. (2003). Groups, growth and trust: Cross-country evidence on the olson and putnam hypotheses. Public Choice, 117:341-355.

Knack, S. and Keefer, P. (1997). Does social capital have an economic payoff? a cross country investigation. Quarterly Journal of Economics, CXII(4):1251-1288. 
Kochanek, S. A. (1993). Patron-Client Politics and Business in Bangladesh. Sage Publications, New Delhi.

Kumar, K. B. and Matsusaka, J. G. (2004). Village versus market social capital: An approach to development. Mimeo, University of Southern California.

La Porta, R., de Silanes, F. L., Shleifer, A., and Vishny, R. (1999). The quality of government. Journal of Law, Economics and Organization, 15(1):222-279.

Lambsdorff, J. G. (2005). Consequences and causes of corruption - what do we know from a cross-section of countries? Diskussionsbeitrag Nr. V-34-05, Universitat Passau.

Licht, A., Goldschmidt, C., and Schwartz, S. (2003). Culture rules: The foundations of the rule of law and other forms of governance. Paper presented at ISNIE 2003.

Liebowitz, S. J. and Margolis, S. E. (1995). Path dependence, lock-in, and history. Journal of Law, Economics, and Organization, pages 205-26.

Lipstein, K. (1957). The reception of western law in India. International Social Science Bulletin, pages 85-95.

Maxfield, S. and Schneider, B. R. (1997). Business and the State in Developing Countries. Cornell University Press, Ithaca, NY.

Myerson, R. B. (1991). Game Theory: Analysis of Conflict. Harvard University Press, Cambridge, MA.

North, D. C. (1990). Institutions, Institutional Change and Economic Performance. Cambridge University Press, Cambridge, UK.

North, D. C. (2005). Understanding the process of economic change. Princeton University Press, Princeton, NJ.

Putnam, R. D. (1993). Making Democracy Work: Civic Traditions in Modern Italy. Princeton University Press, Princeton, NJ.

Putnam, R. D. (2000). Bowling Alone: The Collapse and Revival of American Community. Simon and Schuster, New York.

Rose-Ackerman, S. (1999). Corruption and Government. Cambridge University Press, Cambridge, UK.

Temple, J. and Johnson, P. A. (1998). Social capability and economic growth. Quarterly Journal of Economics, pages 965-990.

Treisman, D. (2000). The causes of corruption: A cross-national study. Journal of Public Economics, 76:399-457.

Uslaner, E. M. (2005). Trust and corruption. In Lambsdorff, J. G., Taube, M., and Schramm, M., editors, The New Institutional Economics of Corruption, pages 76-92. Routledge, New York, NY. 
Wraith, R. and Simpkins, E. (1963). Corruption in Developing Countries. Norton Press. 